\title{
Environments for nursing scholarship and journal impact factor in five countries
}

\section{S. Ketefian' EdD, RN, FAAN, Y.-T. Dai' PhD, RN, S. Hanucharurnkul ${ }^{3}$ PhD, RN, I.A.C. Mendes ${ }^{4}$ PhD, RN \& I.J. Norman ${ }^{5}$ PhD, RN}

\begin{abstract}
I Professor and Director of International Affairs, University of Michigan, School of Nursing, Ann Arbor, MI, USA, 2 Professor, National Taiwan University, School of Nursing, Taipei, Taiwan, 3 Professor, Department of Nursing, Ramathibodi Hospital Faculty of Medicine, Mahidol University, Bangkok, Thailand, 4 Professor and Director, WHO Collaborating Center for Nursing, Research Development, College of Nursing, University of São Paulo at Ribeirao Preto, Brazil, 5 Professor and Associate Dean, King's College London, Florence Nightingale School of Nursing and Midwifery, London, UK
\end{abstract}

KETEFIAN S., DAI Y.-T., HANUCHARURNKUL S., MENDES I.A.C. \& NORMAN I.J. (2010) Environments for nursing scholarship and journal impact factor in five countries. International Nursing Review 57, 343-351

Background: Universities worldwide are seeking objective measures for the assessment of their faculties' research products to evaluate them and to attain prestige. Despite concerns, the impact factors (IF) of journals where faculties publish have been adopted.

Research objective: The study aims to explore conditions created within five countries as a result of policies requiring or not requiring faculty to publish in high IF journals, and the extent to which these facilitated or hindered the development of nursing science.

Design: The design was a multiple case study of Brazil, Taiwan, Thailand (with IF policies, Group A), United Kingdom and the United States (no IF policies, Group B). Key informants from each country were identified to assist in subject recruitment.

Methods: A questionnaire was developed for data collection. The study was approved by a human subject review committee. Five faculty members of senior rank from each country participated. All communication occurred electronically.

Findings: Groups A and B countries differed on who used the policy and the purposes for which it was used. There were both similarities and differences across the five countries with respect to hurdles, scholar behaviour, publishing locally vs. internationally, views of their science, steps taken to internationalize their journals.

Conclusions: In group A countries, Taiwan seemed most successful in developing its scholarship. Group B countries have continued their scientific progress without such policies. IF policies were not necessary motivators of scholarship; factors such as qualified nurse scientists, the resource base in the country, may be critical factors in supporting science development.

Keywords: Brazil, Environments for Nursing Scholarship, Impact Factor, Nursing Science, Publications, Taiwan, Thailand, United Kingdom, United States of America

Correspondence address: Shaké Ketefian, University of Michigan, School of Nursing, 400 North Ingalls, Ann Arbor, MI 48109, USA; Tel: 734-763-6669; Fax: 734-615-3798; E-mail: ketefian@umich.edu.

\section{Introduction}

With the globalization of higher education, more and more institutions worldwide find themselves in a competitive environment; as a result, these institutions are self-consciously seeking to 
improve their standing, prestige and performance indicators. This desire for prestige and high rankings has led institutions to take steps internally to improve their educational offerings and the overall research environments, the resource base, faculty qualifications and facilitation required to enhance faculty research (Freshwater 2006). The efforts to achieve high rankings have led to assessments of faculty's outputs, and the use of bibliometric measures such as impact factor (IF) of journals have come to serve unexpected purposes.

Monastersky (2005) contends that the original developer of the impact factor as well as the Institute for Scientific Information (ISI) have warned about using the IF, intended for journals, in making judgments about individual papers or individual investigators; others have pointed to the flaws and vulnerabilities of the IF (Johnstone 2007). but such cautions have gone unheeded. Monastersky (2005) has provided examples from England where IF is used in hiring decisions; from Spain, where a law rewards those who publish in high IF journals; and from China, where cash bonuses are provided for publishing in high IF journals, and where physics students are required to have published in such journals to be able to obtain their $\mathrm{PhD}$ degrees.

Despite concerns that appear in the literature, however, the IF has assumed widespread use, and is being used to measure the quality of articles, and to evaluate individual faculty in hiring, tenure and promotion decisions. In some countries, IF and other such measures are being used to determine research funding and national priority setting among institutions (Campanario et al. 2006). More recently, editorialists have bemoaned the mis-uses of the IF. The obsession of scientists/authors with these measures is now shared by journals and their editorial teams (Freshwater 2006; Ketefian \& Freda 2009; Smith 2001, 2006), leading to judgments about the quality of an individual's or an institution's work, which then serves as the basis for institutional rankings and allocation of funds to institutions. These and other authors have also noted that the social utility and relevance of research are not necessarily considered in the peer review process of scientific papers that get published in high impact disciplinary journals, while they are major considerations for the professions which provide services to patients.

The tendency to use or mis-use the IF has been facilitated by information technology developments and multiple databases that have made it easy to search for material in any number of configurations. The original databases dealt with the sciences, social science and the humanities, and were brought online with the launch of Web of Science (WoS). There are now databases such as Scopus, Google Scholar and others based on IFs and citation counts.

Research in nursing regarding these issues has been lagging perhaps because few nursing journals are included in the WoS, with relatively low IFs compared with those of other disciplines. A current initiative supported by the International Academy of Nursing Editors has been directed towards increasing the number of nursing journals in the WoS, which now stands at 75 journals; countries represented as of this writing are Australia, Brazil, Japan, Switzerland, the United Kingdom (UK) and the United States of America (USA), which has the majority of the listed journals (59). The reasons for the dominance of USAbased journals may be because of the scale of academic nursing within the USA, the fact that nursing research within researchintensive universities began flourishing there earlier than elsewhere and the fact that USA scholars use and cite mainly authors within their country to the exclusion of scientific works elsewhere. Yet, this is a pattern typical of other disciplines, causing many international scholars much concern, who have noted the dominance of English-language and USA journals.

\section{Impact factor and quality}

One of the concerns with how the IF is used is that it has become a stand-in for quality of individual articles. Several studies reported in the literature address this issue from a variety of perspectives. Holden et al. (2006) studied the predictive validity of IF scores in hiring and promotion decisions of social work faculty; they concluded that use of IF scores in faculty hiring or promotion decisions was not justified (Holden et al., p. 621).

Saha et al. (2003) investigated the relationship between subjective assessment of journal quality and journal IF for general medical journals; 416 physicians in internal medicine and in medical research were asked to rate nine general medicine journals; the results revealed strong correlations between the IF and physician ratings of journal quality $\left(r^{2}=0.82\right.$ for practitioners, $r^{2}=0.83$ for researchers).

In a different type of study, Nieminen et al. (2006) investigated the relationship between specific features of research quality and citation frequency. They found that good reporting of research questions, accurate statistical methods and findings were related to the visibility and prestige of the journal (represented by the two journals with the higher IFs among the four chosen). The authors ascribe these findings to the detailed author guidelines and rigorous peer review process characteristic of the two high IF journals in the study.

Judge et al. (2007) investigated the factors that account for management research article citations, using variables under three groups: article factors, author factors and journal factors. They found that variables within each of these categories play an important role in predicting citation; specific factors relevant here included: clear/readable presentation, number of references cited, prestige of author's affiliation, novelty of idea of the article 
1. Who uses the IF policy?

2. Purposes for which the IF is used.

3. How do nurse scholars behave as a result of policies to publish in high IF journals?

4. What are the hurdles nurse scholars encounter in publishing in top-tier, internationally recognized journals?

5. How do scholars who publish in local/national journals perceive their contributions vs. those who publish internationally?

6. What are the positives, if any, of policies to publish in high IF journals?

7. How would you characterize the current published works in your country?

8. To what extent have there been efforts in your country to internationalize nursing journals? Check those that apply.

9. Is there an Impact Factor [IF] policy in use in your country?

10. Do you or your colleagues agree with the use of the IF?

11. What do you see as the disadvantages in the use of the IF from the standpoint of individual faculty, nursing school/department or the nursing profession?

12. To what extent are university rankings and ratings in your country dependent on the research productivity of the collective faculty?

13. Are there top-tier journals that universities compile in nursing where nursing faculty are urged to publish?

14. High IF journals have been criticized in the literature on various grounds. In your view, to what extent is this the case for high IF journals in nursing?

15. How many nursing journals published in your country are listed in the Web of Science?

16. Do you agree with efforts underway by the International Academy of Nursing Editors to increase nursing journals in the Web of Science?

Note: Questions 1-8 correspond to the items in Table 2.

and subjective prestige of the journal the article appeared in. However, the most important predictor was found to be publication in journals that had high average citation rates, i.e. those that had high IF.

Leung (2007) commented on the article by Judge et al. (2007) from an East Asian perspective; he confirmed the intense pressure felt by East Asian management researchers to publish in high IF journals, and discussed the various consequences of these pressures on Asian management science. He identified consequences both positive (improved research rigor, international recognition received by East Asian scholars), as well as negative ones (scholars working in areas popular in the West, rather than doing research needed in the region that demonstrates its social relevance).

Brazil has adopted policies on publication in high IF journals; both government agencies and universities now place heavy emphasis on this policy for determination of faculty's academic rank, institutional prestige and funding to universities. In Taiwan government agencies now promulgate policies basing funding and national rankings of universities on their research performance, using the number of articles published by faculties in several databases of the ISI, mainly the science, social science and humanities. Similarly, Thai government agencies have adopted policies regarding publication in high IF journals; both government and universities now place great emphasis on this policy for determination of the faculties' academic rank, institutional prestige and funding to universities.

At the time of data collection, no formal national policies existed regarding publication in high IF journals within the UK, although departments are said to urge their faculties to publish in top-tier journals listed in the ISI. Similarly, the USA does not have national policies regarding publication venues. It is a unique aspect of the higher education system that allows universities latitude in how quality is determined. Professional groups that set accreditation criteria and standards and accredit institutions and disciplines are influential. There are commonly understood journals in the country - general, specialized and interdisciplinary - in which faculties are encouraged to publish. However, faculty committees address the issue of quality of scientific contributions to nursing and to the welfare of care recipients by calling upon external peer evaluators.

No studies could be located in nursing on how the implementation of such policies could affect, directly or indirectly, the development of nursing science, by creating environments within which scientific development can flourish or might be hindered.

The objective of this study was to explore conditions created within five countries as a result of national policies requiring or not requiring faculty to publish in high IF journals and the extent to which these facilitated or hindered the development of nursing science. A comparison will be made between the countries that have such policies with those that do not. The specific issues to be explored are reflected in the questions posed to the respondents in Table 1.

\section{Definition}

Impact factor is the number of citations to articles published in a journal in two preceding years divided by the total number of articles in that journal in those 2 years (Amin \& Mabe 2000). 


\section{Methods}

The design is a multiple case study of Brazil, Taiwan, Thailand, the UK and the USA, with the unit of analysis being the country. According to Woods \& Catanzaro (1988), case studies are 'naturalistic studies'... that are 'not controlled by the investigator', ... in which 'design is determined by the question posed' (p. 156).

The countries were selected on the basis of what was 'known' about national policies, to enable comparison between them. At the time of data collection, Brazil, Taiwan and Thailand (Group A) had government policies requiring publication of faculty in high IF journals, whereas the UK and the USA (Group B) did not.

\section{Selection of institutions and participants}

One key informant was identified from each country to provide country-specific information regarding institutional ratings and/or rankings and to assist in identifying study participants. The key informants were senior academics, holding the rank of professor in a major university, most of whom serve in editorial roles, had been involved in professional organizations over many years and had overall familiarity with nursing programmes and nurse academics in the country.

Informants were asked to identify the highest ranked institutions with nursing doctoral programmes in their countries; the systems varied in how such institutions were designated, as well as in the number of nursing doctoral programs within a given country. One person, suggested by the country informant, from each of the identified institutions was invited to participate. The respondents held the rank of professor or associate professor and because of their senior rank, were familiar with their respective national policies, the state of nursing science in their countries, had taught in their doctoral programmes and had scholarly publications. They were thought to be in the best position to provide the needed information to address the issues being explored in this study. In the event individuals declined or did not respond to the initial invitation, alternates, meeting similar criteria, were sought.

Given the geographic diversity of the respondents, the most realistic method for collecting data was through a questionnaire. The individual respondents were asked to provide information on their country, and the impact these may have on the nursing scholarly community. In view of the purpose of this study, it was more important to have an equal number of respondents per country rather than proportional representation. Given the doctoral programme variations (seven in Thailand, over 100 in the USA), five respondents per country were deemed sufficient, and this was also feasible within the resources of the study. To allow for non-respondents, the initial invitation was extended to 7-8 individuals from each country.

\section{Procedures}

Institutional Review Board approval was obtained from the institution of the first author. Because of the low risk posed by the study, the IRB did not require signed consent, but required that a letter with the elements of informed consent be provided to the participants for information only. Identified individuals were invited to participate by the investigator through an invitation letter, providing information on the study, and the approved consent for reference. Several reminder letters were sent; within 8 weeks five responses were received from each country. All communication occurred electronically.

\section{Study instrument}

A questionnaire was developed for data collection to ensure that respondents provide information on a consistent set of issues. The questionnaire sought to understand the extent and purposes for which systems in the country made use of IF of journals in which their faculties publish. Further, it sought to explore the issues that are the focus of this study.

The questionnaire development was guided by the literature in generating the questions. A draft was reviewed by four researchers from four countries for clarity and relevance of the items to the study objective. Revisions were made accordingly. Eight of the questions present a list of statements as options, five questions require yes/no responses to be checked and three questions require narrative answers, for a total of 16 questions. Table 1 provides the list of questions.

\section{Data analysis}

The responses to questions providing options were summarized in table form. Comments and narrative responses were summarized and presented descriptively. The country informant was critical in providing background on the country and in interpreting statements from respondents that could be understood only by knowledge of the context. This approach is in line with the literature on the nature of case studies where data can legitimately be obtained from multiple sources (Woods \& Catanzaro 1988).

\section{Results}

Results are reported for two groups of countries. We summarize and describe the responses to the eight questions where options were provided in the questionnaire. First, for the three countries where the requirement for publication in high IF journals exists, namely Brazil, Taiwan and Thailand (Group A); this is followed by a summary for the countries where such requirements do not 
Table 2 Summary of Responses to Selected Items for Five Countries: Brazil (Br), Taiwan (Tw), Thailand (Th), United Kingdom (UK), United States (USA)

Questions and options

Frequencies (no. per country $=5$ )

\begin{tabular}{llllll}
\hline \multicolumn{2}{ll}{ Group A } & & & Group B \\
$\quad T w$ & $T h$ & & UK & USA
\end{tabular}

1. Who uses IF

(a) University administrators

(b) School of nursing/department

(c) Government agency

(d) Faculty committees

2. Purpose for which IF is used

(a) As measure of individual's productivity

(b) As measure of a group's productivity

(c) As measure of school/department quality

(d) To assure high ranking of institution in national and international surveys

(e) As measure of journal quality

3. How nurse scholars behave as a result of policy requiring publication in high IF journals

(a) Scholars compete rather than cooperate

(b) Scholars publish in journals of other countries

(c) Scholars want to publish in high quality journals regardless of their IF

4. Hurdles encountered in publishing in top tier Journals

(a) Insufficient language skills

(b) Not familiar with top tier journals or their guidelines

(c) Topics of interest to researchers do not interest such journals

(d) Those with graduate degrees from overseas are at an advantage

5. Compare/contrast those who publish locally vs. those who publish internationally

(a) Locally published authors are studying important problems in their country

(b) Those who publish internationally add prestige to their institution and country

(c) Country cannot benefit from international publications

(d) Publishing internationally means focus on health problems of interest to journals rather than own country

6. Positive aspects of policy to publish in high IF journals has meant that

(a) There is greater methodological rigor in research in the country

(b) There is stronger theoretical grounding in published papers

(c) Graduate level training in research has improved in the country

7. Current published work in your country

(a) Are trailblazing efforts in theory or methodology

(b) Are responsive to health needs of the country

(c) Are of interest to investigators but not of value to population

(d) Frame practical applications of research for health problems of country

(e) Frame practical applications of research to health problems of other regions

(f) Replication of work done elsewhere for their relevance to local needs

8. Efforts to internationalize their journals

(a) International members added to journal editorial boards or as assistant/associate editors

(b) International members are added as manuscript reviewers

(c) Researchers from the country serve on editorial boards of journals in other countries

(d) Researchers from country serve as reviewers for journals in other countries

(e) Any of the above steps have strengthened the quality of the journals in the country

$N=25$.

exist, namely the UK and the USA (Group B). Table 2 summarizes responses to these questions for all countries in frequencies. This is followed by a comparison of the two groups. Only noteworthy findings will be highlighted in the narrative below. Rel- evant comments provided by the respondents that might elucidate their responses are incorporated in the narrative. We include summaries of answers provided to questions requiring free responses under the relevant topics. In describing the find- 
ings and referencing the items in Table 2, frequencies of 3 and above will be referred to as the 'majority' of respondents.

\section{Group A: Brazil, Taiwan, Thailand}

Is there a policy in your country regarding IF? If yes, who uses the policy? All three countries confirmed that an IF policy exists; however, the policy was not implemented through faculty committees dealing with recruitment and promotion in Brazil and Thailand. Nursing administrators did not seem to enforce the policy in Thailand (readers are referred to Table 2 throughout the presentation of results).

Purpose

There was general similarity across countries in the purposes for which the policy was used, except in Brazil, where there appears to be less concern with institutional ranking, and greater concern with research funding levels.

\section{Scholar behaviours}

There was agreement by all that such policies create competition and lead scholars to publish in journals from other countries. The desire to publish in high quality venues regardless of IF was identified by a slight majority of Brazilian respondents.

\section{Hurdles}

All agreed about language hurdles (concern with English) and the perception that topics that interest investigators do not interest top-tier journals. Respondents from Taiwan and Thailand held the view that those with graduate degrees from overseas were at an advantage, presumably because they would have become socialized into these matters during their education; however, this was not the case with Brazil, which also indicated lack of familiarity with top-tier journals. In additional comments, all were critical of the policy in that it disadvantaged nursing in resource allocation, funding for research and for doctoral students. Thai respondents felt a bias existed against nurse scholars and their work. This group provided ideas on how perceived hurdles might be addressed, including hiring English language editors, recognizing nurse scientists by awards and building research programmes with interdisciplinary teams.

\section{On publishing locally vs. internationally}

All three country respondents agreed that those publishing locally addressed important problems of the country and those publishing internationally added prestige to their institutions and countries. Thai respondents seemed to have a negative view of international publications, indicating that the country cannot benefit from such publications, and that such publications meant that scholars focus on health problems of interest to those journals rather than to their own country. Respondents further stated: health problems are global; research should be generalizable and needs to be shared globally; quality assessments need to be based on the usefulness of research in meeting national needs, and research should be brought to practising nurses.

Positive aspects of policy for country

Brazil and Thailand stated that research training has improved at the graduate level, and Thailand indicated that both theoretical and methodological rigor of published papers had improved. Taiwanese respondents indicated that theoretical grounding of published papers had improved.

Characterizing published works in their country

All country respondents stated that they involved replication of work done elsewhere and that they frame practical applications of research to health problems of other regions. Responses from Taiwan and Thailand indicated that their publications were responsive to health needs of the country; Thai respondents stated that they framed the practical applications of research for health problems of their country, and that the topics studied were of interest to investigators but not of value to the population; these two statements seem contradictory. Respondents from Taiwan commented that IF journals were not the venues that practising nurses chose to read, especially because these nurses were critical in applying new knowledge to practice.

Efforts to internationalize journals

Each country respondents chose at least three of the five methods listed to internationalize journals. In the case of Brazil, while they identified recruiting international members for different types of service for their journals, the reverse was not the case, in that Brazilian scholars did not similarly serve in various roles for journals of other countries. Both Brazil and Thailand have established criteria for classifying their journals into national and international categories.

\section{Group B: UK, USA}

Is there a policy in your country regarding IF? If so, who uses the policy? Responses from the UK and USA confirmed that there is no policy on IF, although a modest majority from both countries stated that nursing schools/departments use it and the UK respondents indicated that faculty committees (dealing with recruitment and/or promotion) also use it.

Purpose

UK respondents indicated that the policy was used as a measure of journal and departmental quality. No other options were 
chosen by a majority. In comments, UK respondents stated that the policy is helpful in resource allocation and benchmarking.

Scholar behaviours

Respondents from both countries agreed that the policy led to competition, UK respondents indicated that scholars publish in journals of other countries and those from the USA stated that scholars want to publish in high-quality journals regardless of their IF. UK respondents agreed that when the IF is required by the new Research Excellence Framework, expected to be highly influential, which is to replace the current Research Excellence Exercise (Nolan et al. 2008), scholar behaviours will change, and expressed concern that different forms of publications such as books, book chapters, monographs, would be devalued. USA respondents commented that the quality of studies was more important than the journal IF.

Hurdles

Slight majorities from both countries stated that topics of interest to researchers do not interest such journals. USA respondents chose insufficient language skills and those with graduate degrees from overseas were at an advantage. Respondents from both countries felt the system was unfair in that artificial ways were used to increase journals' IF, that it did not address knowledge use by clinical nurses. UK respondents stated that nursing needs to create knowledge and develop evidence-based practice and knowledge transfer strategies, that the system is biased towards North American publications and basic science fields. They also addressed ways of dealing with hurdles, stating that working with large, interdisciplinary teams will help improve research methods and facilitate the mentoring of junior colleagues. USA respondents commented on the need to publish research in journals of other disciplines, publishing as soon as possible upon completion of a study, and the need to work with editors of non-USA journals to understand their challenges.

On publishing locally vs. internationally

Respondents from both countries agreed that locally published authors were addressing problems of their country; the UK respondents further stated that those publishing internationally added prestige to their countries and institutions; they commented that there was a need to balance choice of high IF journal with a need to reach audiences that will use the results of the research, rejecting a dichotomy, stating that the aim of scholars should be to publish in high-quality journals, that research can have global implications even if done locally.

Positive aspects of policy for country

Both countries indicated that there was greater methodological rigor in published research, that it was good for the prestige of the profession; USA respondents indicated that the theoretical grounding of published papers was stronger. UK respondents stated that the policy was a performance indicator for journal editors.

Characterizing published works in their country

There were no areas of agreement between the two countries. USA respondents chose the options that the current published works represented trailblazing efforts, were responsive to country needs and framed the practical applications of research for the country. UK respondents chose the options that published works were of interest to investigators but not to the population, that they framed the practical applications of research for other regions. Comments from the UK were that well-known researchers are able to achieve a balance between topics that are publishable in high IF journals and at the same time, be useful to local populations.

Efforts to internationalize journals

UK respondents chose all options given, stating that the listed steps have strengthened the quality of their journals. USA respondents chose only that researchers from the country served as reviewers for journals in other countries.

\section{Comparison of groups and discussion}

Differences were noted across groups A and B countries, mainly in who makes use of the IF policy, and the purposes for which it is used, supporting the classification of the countries into two groups.

In group A countries, criticism of the policy and the hurdles were consistent; yet, Brazil and Taiwan, unlike Thailand, have embraced the policy, with efforts to implement it. Some constructive recommendations were made by Thai respondents for dealing with obstacles.

Other similarities/differences were noted that cross the boundaries of the two groups. For example, Taiwan and Thailand perceived the greatest hurdles while UK but not USA respondents perceived the lowest hurdles. With respect to how national vs. international publications are viewed, UK and USA respondents seemed to reject the dichotomy, while those from Thailand perceived the distinction more sharply. As to how each country's science was viewed, Thai respondents saw their science most favourably, while those from Brazil saw their science least favourably. On efforts to internationalize their journals, Brazil and the USA seem to have taken the least number of steps, while the UK, Thailand and Taiwan have taken active steps.

In a recent study of international differences in nursing research for 2005-06, Polit \& Beck (2009) extracted various characteristics of published papers from eight nursing journals, five 
from the USA, three from the UK. Fifteen countries were represented in their sample of articles, according to country of first author's institution. The four countries with the highest percentage of total publications represented were: USA, 31\%; UK, 17\%; Sweden, 8.6\%; and Taiwan, 7.4\% during the 2 years; the three countries of interest were among the top-ranked in percentage of quantitative studies, intervention studies and funding received. These data suggest strong cadres of researchers in the USA, UK and Taiwan who are conscious of the importance of publishing in international venues. This strength is impressive on the part of Taiwan, when considering the small size of the country relative to the USA and the UK, and the fact that it did not have any nursing journals in the WoS. The study did not include Latin American countries or Thailand.

In another study, Mendoza-Parra et al. (2009) analysed the visibility of Latin American nursing research for 46 years, extracted from international and regional databases. They addressed the issues of limited nursing research and lack of international visibility of the region's research, identifying the nursing community's limited knowledge and experience in conducting research as one factor. Yet, they identified Brazil as producing a full $31.9 \%$ of the total number of publications analysed, and commented on the leadership of Brazilian nursing in the past 20 years in developing graduate/doctoral education and nursing research. These findings on the leadership of Brazilian nurses are indeed positive; while acknowledging this, the authors pointed to the need for integration of Brazilian science with scientific communities globally.

Brazil and Thailand have established their own criteria to classify their journals into national and international. While this would seem positive, the presence of domestic journals classified as 'international' might lull their scholars into equating these with truly international journals and hinder them from the steps necessary to reach out, interact and collaborate with broader scientific communities globally.

In some respects, group $\mathrm{B}$ countries were similar to those of group A, but the UK seemed more so, such as in responses to the consequences of publishing nationally vs. internationally, and in steps taken to internationalize their journals, while the USA has taken the least number of steps in embracing foreign scholars' involvement. Yet, it was the only country viewing its research as representing 'trailblazing efforts in theory and methodology'. The number of USA journals in the WoS dominates the nursing list (59). Many countries consider USA scholars as somewhat parochial in their scholarly habits, such as in publishing in their own journals and in their limited use of scholarship done elsewhere. The fact that they have many choices as venues for their works may be a factor. In several areas, USA responses differ substantially from the other four countries, such as on purposes of IF use (\#2), scholar behaviour (\#3c), local vs. international publications (\#5) and internationalizing journals (\#8).

It can be concluded that required policies seem to have created a degree of intellectual foment in group A countries, with Taiwan having the most successful outcome, as represented in the international publications of its scholars, with Brazil and Thailand making efforts in ways unique to themselves, and mindful of the need to increase their international publications. In group B countries, where such policies were not in place, scholarly progress has continued apace in varying degrees, suggesting that in the case of the UK and the USA, the spur of such policies was not necessary to motivate scientific activity. Rather, other factors are also likely to be crucial, such as the availability of qualified nurse scientists, the resource base within the country and the provision of myriad forms of facilitation necessary to support a research infrastructure.

\section{Implications}

Several implications can be drawn, based on study findings, respondent comments and the authors' knowledge of the state of the nursing literature in their countries:

1 Impact factors are likely to have increasing influence on publication behaviours, as they are a relatively inexpensive way to monitor scholars' publications; yet, they are only one type of measure. Efforts need to focus on developing measures of the real impact of published works on the care of patients, on policy and other domains of nursing.

2 IFs vary across disciplines. More meaningful results can be obtained by comparing IFs within disciplines and across similar types of institutions.

3 With the emphasis on interdisciplinary research, it appears that many nurses are publishing in journals of other disciplines; we may see an increase in this trend as the drive to scholarly productivity becomes more institutionalized. Yet, it is important for nurse scholars to continue submitting high-quality papers to nursing journals, as scientific journals are critical to promoting the development and dissemination of disciplinary knowledge. 4 Journals need to clarify the definition of 'international' to encompass research reports on a local issue that is nonetheless of interest to an international audience.

\section{Limitations}

Several limitations of this research can be highlighted in assessing the significance of the findings. As a case study, only five participants were included from each country, which may not reflect the full spectrum of views. The questionnaire has face validity only, and was in English; this may have caused comprehension difficulties for some participants. Nevertheless, these findings indicate current trends and views; the authors hope they 
will stimulate reflection, further research on the subject and consideration on ways to increase the IF of nursing journals.

\section{Ethical approval}

The study was approved by the Human Subject Review Committee of the first author's institution, to assure that the rights of subjects are protected. The project did not entail an experiment. Given the non-intrusive nature of the study, the Committee approved the study, but did not require that subjects be asked to sign a consent form. It did require that a form prepared describing the study and the rights of subjects be provided to each participant for information only. The requirement was complied. All solicitation of subjects from the five countries, and distribution of the questionnaire and the consent information, including follow-up, was done by the senior author.

\section{Author contributions}

Dr Ketefian provided overall leadership for the project regarding all elements entailed in conducting research; she is the senior and corresponding author. Professors Dai, Hanucharurnkul, Mendes and Norman were involved and participated in conception and design, participated in subject recruitment from their respective countries, provided guidance on analysis of the data, provided relevant background information on their countries during the drafting of the initial manuscript, participated in the substantive revision of the manuscript and have approved the final version for submission.

\section{References}

Amin, M. \& Mabe, M. (2000) Impact factors: use and abuse. Perspectives in Publishing, 1, 1-6 (Elsevier Science).

Campanario, J.M., Gonzales, L. \& Rodriguez, C. (2006) Structure of impact factor of academic journals in the field of education and educational psychology: Citations from editorial board members. Scientometrics, 69 (1), 37-56.
Freshwater, D. (2006) Impact factors and relevance of research outputs: one step forward, two back? Journal of Psychiatric and Mental Health Nursing, 13, 473-474.

Holden, G., Rosenberg, G., Barker, K. \& Onghena, P. (2006) An assessment of the predictive validity of impact factor scores: implications for academic employment decisions in social work. Research on Social Work Practice, 16 (6), 613-624.

Johnstone, M. (2007) Journal impact factors (IF): implications for nursing journals and the nursing profession. International Nursing Review, $\mathbf{5 4}$ (1), 35-40.

Judge, T.A., Cable, D.M., Colbert, A.E. \& Rynes, S.L. (2007) What causes a management article to be cited - article, author, or journal? Academy of Management Journal, 50 (3), 491-506.

Ketefian, S. \& Freda, M.C. (2009) Impact factors and citation counts: a state of disquiet. International Journal of Nursing Studies, 46 (6), 751752.

Leung, K. (2007) The glory and tyranny of citation impact: an East Asian perspective. Academy of Management Journal, 50 (3), 510-513.

Mendoza-Parra, S., et al. (2009) Visibility of Latin American nursing research (1959-2005). Journal of Nursing Scholarship, 41 (1), 54-63.

Monastersky, R. (2005) The number that's devouring science. The Chronicle of Higher Education, 52 (8), A12.

Nieminen, P., Carpenter, J., Rucker, G. \& Schumacher, M. (2006) The relationship between quality of research and citation frequency. $B M C$ Medical Research Methodology, 6, 42-49.

Nolan, M., Ingleton, C. \& Hayter, M. (2008) The Research Excellence Framework (REF): a major impediment to free and informed debate? International Journal of Nursing Studies, 45 (4), 487-488.

Polit, D.F. \& Beck, T.C. (2009) International differences in nursing research, 2005-2006. Journal of Nursing Scholarship, 41 (1), 44-53.

Saha, S., Saint, S. \& Christakis, D.A. (2003) Impact factor: a valid measure of journal quality? Journal of Medical Library Association, 91 (1), 42-46.

Smith, R. (2001) Measuring the social impact of research; difficult but necessary. British Medical Journal, 323, 328.

Smith, R. (2006) Commentary: the power of the unrelenting impact factor - is it a force for good or harm? International Journal of Epidemiology, 35, 1129-1130.

Woods, N.F. \& Catanzaro, M. (1988) Nursing Research: Theory and Practice. C. V. Mosby, St. Louis, MO. 